\title{
ACCURACY ENHANCEMENT OF ELECTROTECHNICAL SYSTEM FOR BULK MATERIAL BATCHING
}

Victor G. Bukreev, Sergey V. Lyapushkin ${ }^{\mathrm{a}}$, Nikolay V. Gusev

National Research Tomsk Polytechnic University, 634050 Tomsk, Russia

\begin{abstract}
In the paper an automatic system for batching and mixing the components of combined feed is considered. A novel algorithm has been proposed for the batching error correction caused by mass of the material column dropping into the batching bin. The proposed algorithm has been validated in a simulation model and in an experimental facility.
\end{abstract}

\section{Introduction}

Labour productivity and manufacturing efficiency are mainly determined by degree of workflow automation and error-free information about supply streams and products quality. It is particularly topical in food industry.

Functional diagram of automatic system for batching and mixing the components of combined feed is shown in Figure 1. The system consists of [1]: 6 feed bins (FB), which contain the components that have to be batched (barley, peas, wheat bran, wheat, sunflower meal, concentrate, vitamin supplement); 6 screw feeders (SF) driven by electric induction motors of $3 \mathrm{~kW}$ capacity; batching bin with handling capacity up to $1000 \mathrm{~kg}$, which is mounted on 3 weight strain gauges (WSG); blending hopper driven by electric induction motor of mixer of $15 \mathrm{~kW}$ capacity and by a motor of ripper; dispatch bin for finished product with capacitance level sensor; transport subsystem for finished product.

Grain raw material is input into the feed bins from car terminal. Loading one bin of 50 tons capacity takes no less than 3 hours. After loading of the feed bins the components are input in their turn into batching bin, where according to required formula the batching is carried out. Signals that are proportional to current weight are read from 3 strain gauges and come into normalizing adding amplifier (NAA), where they are added, normalized into standard current signal and is input into microcontroller. After finishing the batching process of all components the bulk is input into blending hopper. Blending time can be varied 1 to 3 minutes depending on the chosen formula. The resulted mix is output by conveyer of finished product. Shipment of finished product is carried out by means of car terminal with capacity of 15 tons per hour. Motors of screw feeders are powered by one frequency converter by means of relay switching unit (RSU1) controlled by microcontroller. Mixer motor (M8) and ripper motor (M9) are powered from the power supply line by means of relay switching unit (RSU2), which is controlled by microcontroller.

a Corresponding author: 1sw777@mail.ru 


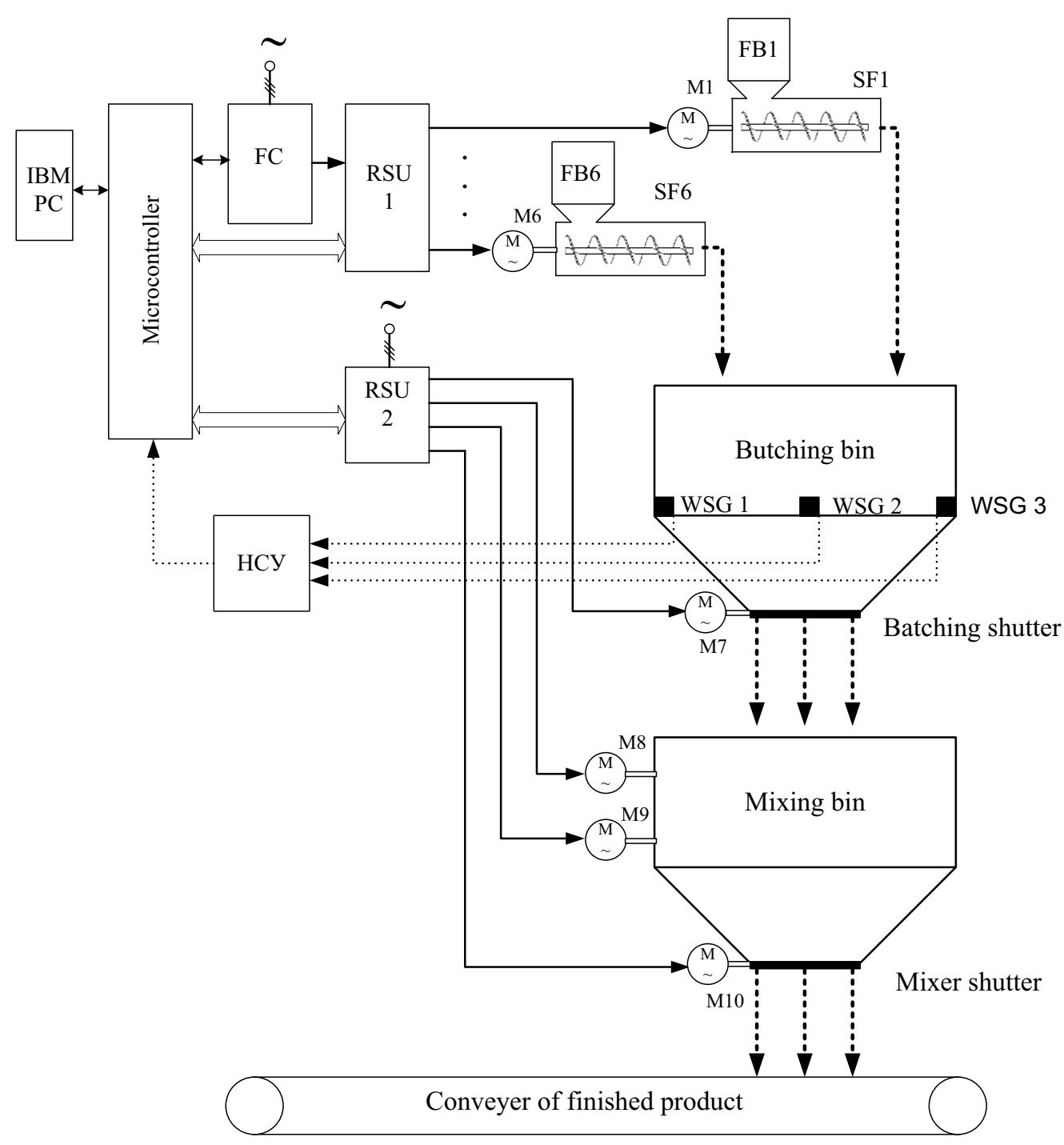

Figure 1. Functional diagram of automatic system for batching and mixing components of combined feed

\section{Correction algorithm for batching error caused by mass of dropping column of material}

While batching bulk solids the strain gauges register the weight of material, which is actually in the bin. If the weight of the dropping column of material, which is in the air, is not taken into account, a significant total batching error can be obtained as a result. In some batching systems the batching mass of the dropping column can reach up to several hundreds kilograms.

Compensation of the mass of dropping column should be carried out at reference forming for the control system. The mass is not registered by the weight sensors, but it is already within the bin. To take it into consideration you need to add the precalculated mass of the dropping column to the feedback signal.

Measured value of mass of batched material in the bin is input into the control system. If density $\rho$ of batching material is known, then volume of material in the bin can be determined in terms of expression:

$$
V=\frac{m}{\rho} \text {. }
$$

Volume, which occupies the batching material in the bin in form of a cube, can be determined in terms of formula:

$$
V=a \cdot b \cdot h_{m}
$$

where $h_{m}$-is height of the material; $a \cdot b-$ is the base area.

The height of the material is determined by:

$$
h_{m}=\frac{V}{a \cdot b} .
$$

Therefore the height of dropping column is determined in terms of:

$$
h_{s t}=h_{0}+\left(h_{b}-h_{m}\right) \text {, }
$$


where $h_{0}$ - is height between the screw and the bin; $h_{b}-$ is the bin height.

Area of dropping column can be determined from geometrical parameters of screw in terms of formula:

$$
S_{s t}=\frac{\pi}{4} \cdot\left(D_{0}^{2}-d_{0}^{2}\right)
$$

As a result the mass of dropping column is determined in terms of expression:

$$
m_{s t}=S_{s t} \cdot h_{s t} \cdot \rho_{\text {nas }},
$$

where $\rho_{\text {nas }}-$ is apparent density of batched material.

As a result we get formula:

$$
m_{s t}=\left[\frac{\pi}{4} \cdot\left(D_{0}^{2}-d_{0}^{2}\right)\right] \cdot\left[h_{0}+\left(h_{b}-\frac{m}{\rho \cdot a \cdot b}\right)\right] \cdot \rho_{\text {nas }} .
$$

For a bin made as truncated trapezoid with a quadrate as a base the mass of dropping column is determined in terms of expression:

$$
m_{s t}=\left[\frac{\pi}{4} \cdot\left(D_{0}^{2}-d_{0}^{2}\right)\right] \cdot\left[h_{0}+\left(h_{b}-\frac{m \cdot 3}{\rho \cdot c \cdot(d \cdot e+\sqrt{d \cdot e \cdot a \cdot b}+a \cdot b)}\right)\right] \cdot \rho_{\text {nas. }}
$$

Thereafter the batching error caused by mass of dropping column of material can be determined in terms of formula:

$$
\Delta m=m_{z a d}-\left(m_{\mathrm{os}}+m_{\mathrm{s} t}\right),
$$

where $m_{z a d}$ - is reference mass of material; $m_{\hat{1} \mathrm{~s}}-$ is mass value according to feedback signal.

To research the proposed solutions an experimental testbench has been developed in Department of Electric Drive and Equipment of Tomsk Polytechnic University.

The whole equipment from middle level of the workflow automatic control system and partly from lower level is located inside nonventilated cabinet (fig. 2-a).

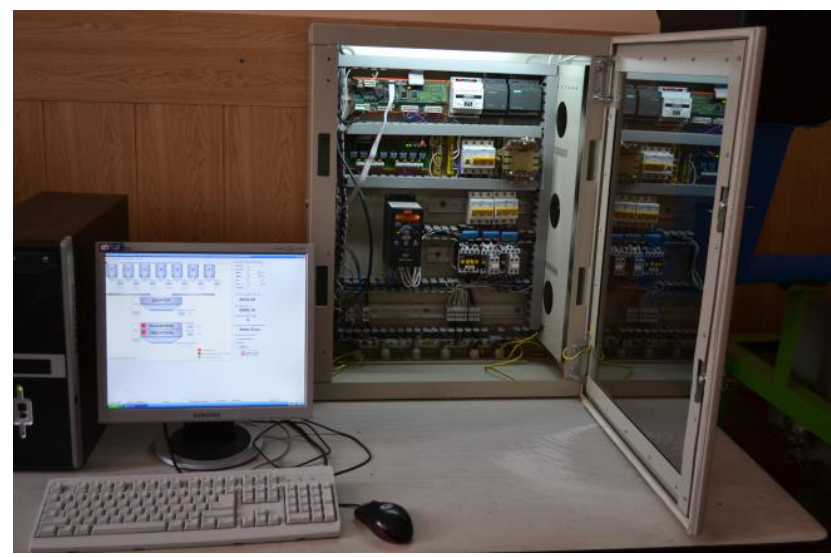

(a)

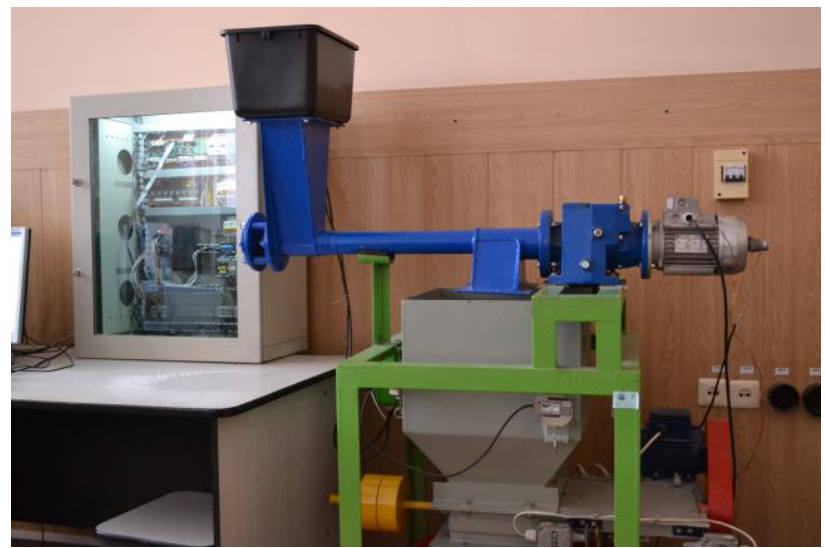

(b)

Figure 2. Experimental testbench of the batching system of bulk materials

Mechanics of experimental testbench that consists of flexible helical screw, batching bin, which is suspended on 3 weight strain gauges, and batching shutter is shown in figure 2-b.

Experimental research has been carried out for batching 1 kilogram of polypropylene without the error correction algorithm (fig. 3) and for enhanced control program with taking into account the algorithm (fig. 4). Results of experiments show that without the correction algorithm the batching error is $0.0859 \mathrm{~kg}(8.59 \%)$. After implementing the correction the error is decreasing to $0 \mathrm{~kg}$. Obtained results show that with required capability in practice the reduction of the batching error almost for $9 \%$ can be achieved. In diagrams $\omega, m$ are the screw speed and mass of batching material, which are determined experimentally; $m$ ' is the batched weight that is registered in simulation model with the correction algorithm of the batching error caused by mass of dropping column of material. 


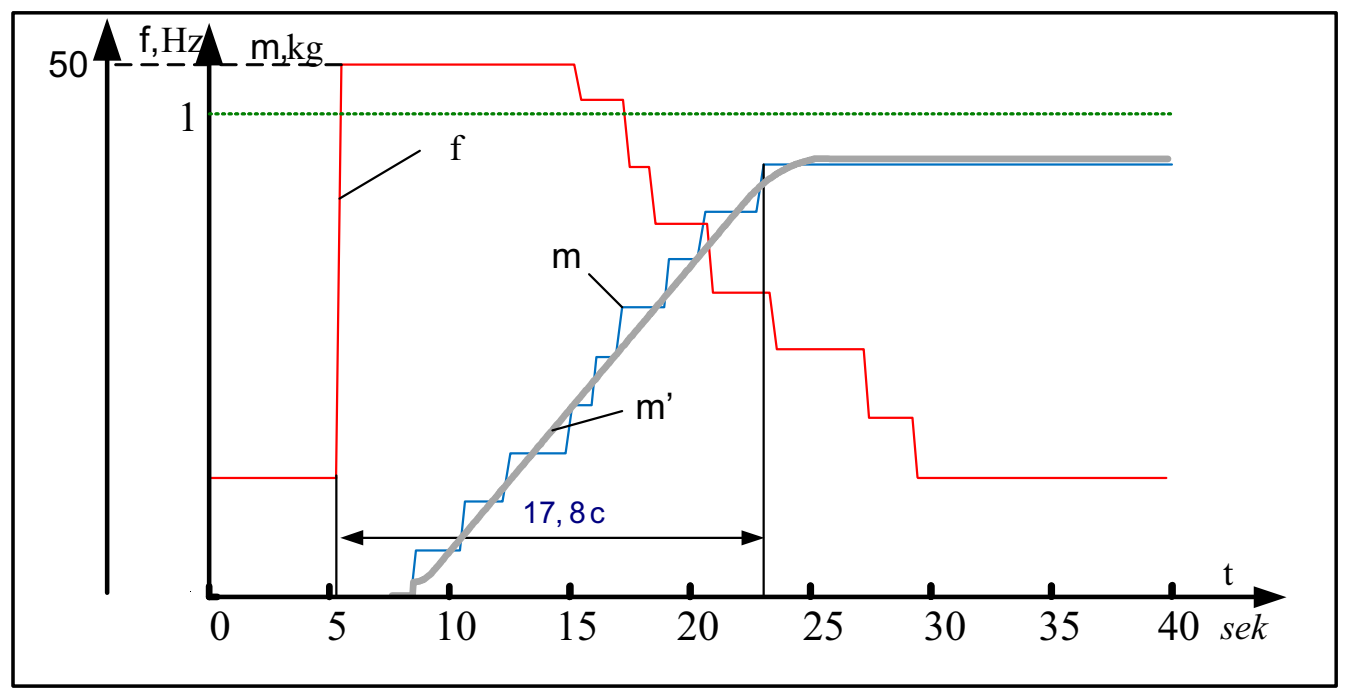

Figure 3. Batching transients without algorithm of the error compensation

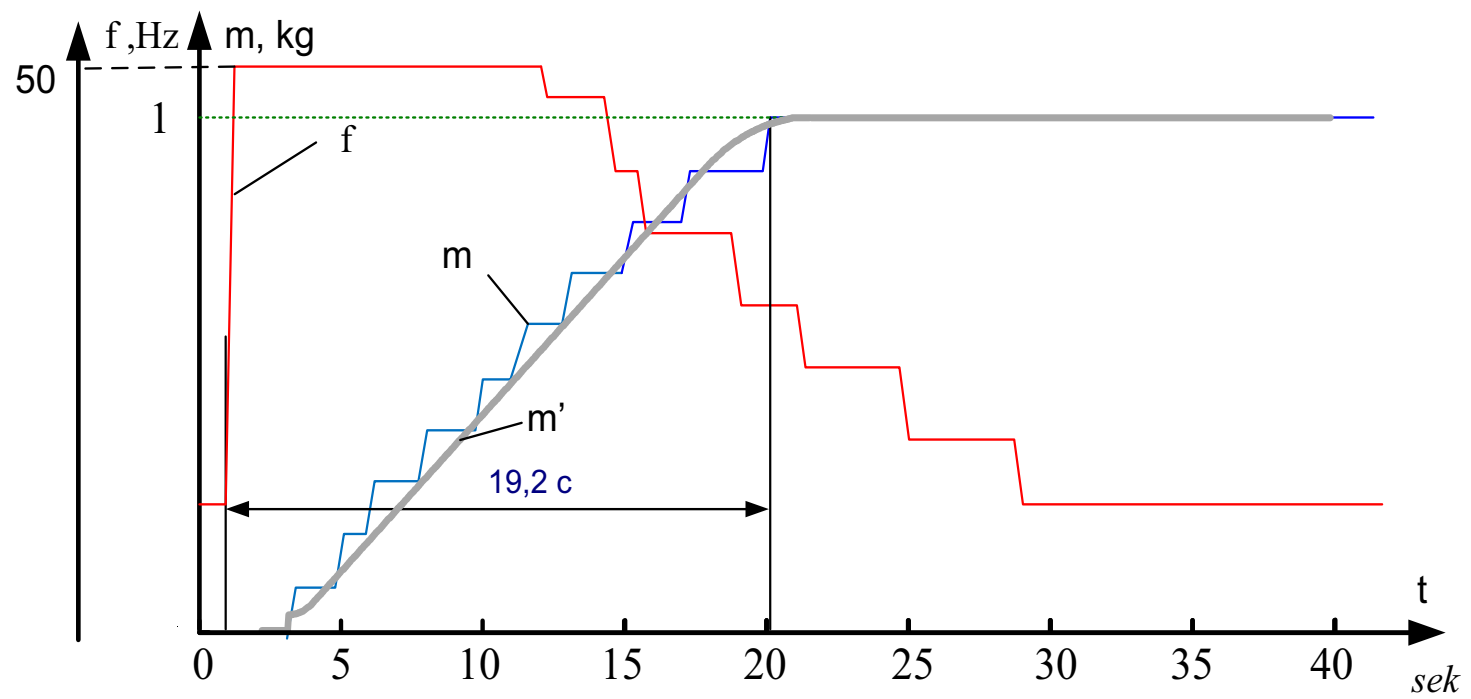

Figure 4. Batching transients with compensation algorithm of the error caused by mass of dropping column of material

The work is performed according to the state task "Science" 2.13.18.2014

\section{References}

1. Букреев В.Г., Гусев Н.В., Нечаев М.А., Краснов И.Ю., Кремис С.Ю.

ACУ ТП производства комбикормов на базе контроллера Fastwel RTU188-BS/ Журнал «Современные Технологии Автоматизации», изд.2006 г., №1.

2. Каталымов Анатолий Васильевич. Дозирование сыпучих и вязких материалов / А. В. Каталымов, В. А Любартович. - Л. : Химия, 1990. - 240 с..

3. Григорьев Алексей Михайлович. Винтовые конвейеры / А. М. Григорьев. - М. : Машиностроение, 1972. - 184 с. 